\title{
Epigenetic regulator MLL2 shows altered expression in cancer cell lines and tumors from human breast and colon
}

\author{
Thanemozhi G Natarajan*+1, Bhaskar V Kallakury², Christine E Sheehan³, Margaret B Bartlett¹, Natarajan Ganesan1, \\ Anju Preet ${ }^{1}$, Jeffrey S Ross ${ }^{3}$ and Kevin T FitzGerald
}

\begin{abstract}
Background: MLL2, an epigenetic regulator in mammalian cells, mediates histone 3 lysine 4 tri-methylation (H3K4me3) through the formation of a multiprotein complex. MLL2 shares a high degree of structural similarity with $M L L$, which is frequently disrupted in leukemias via chromosomal translocations. However, this structural similarity is not accompanied by functional equivalence. In light of this difference, and previous reports on involvement of epigenetic regulators in malignancies, we investigated MLL2 expression in established cell lines from breast and colon tissues. We then investigated MLL2 in solid tumors of breast and colon by immunohistochemistry, and evaluated potential associations with established clinicopathologic variables.

Results: We examined MLL2 at both transcript and protein levels in established cell lines from breast and colon cancers. Examination of these cell lines showed elevated levels of MLL2. Furthermore, we also identified incomplete proteolytic cleavage of MLL2 in the highly invasive tumor cell lines. To corroborate these results, we studied tumor tissues from patients by immunohistochemistry. Patient samples also revealed increased levels of MLL2 protein in invasive carcinomas of the breast and colon. In breast, cytoplasmic MLL2 was significantly increased in tumor tissues compared to adjacent benign epithelium ( $p<0.05)$, and in colon, both nuclear and cytoplasmic immunostaining was significantly increased in tumor tissues compared to adjacent benign mucosa $(p<0.05)$.

Conclusion: Our study indicates that elevated levels of MLL2 in the breast and colon cells are associated with malignancy in these tissues, in contrast to MLL involvement in haematopoietic cancer. In addition, both abnormal cellular localization of MLL2 and incomplete proteolytic processing may be associated with tumor growth/progression in breast and colonic tissues. This involvement of MLL2 in malignancy may be another example of the role of epigenetic regulators in cancer.
\end{abstract}

\section{Background}

MLL2 (MLL) [Swiss-Prot: Q9UMN6] is a member of the $\mathrm{MLL} /$ trx family of proteins. It contains several evolutionarily conserved domains [1] including AT hooks at the Nterminus, cluster of PHD (plant homeodomain) zinc fingers associated with a bromodomain, and a SET (suppressor of variegation, enhancer of zeste, trithorax) domain at the C-terminus [1]. The full length MLL2 (MLL2 $\left.{ }^{\mathrm{FL}}\right)$ is an

* Correspondence: tg24@georgetown.edu

1 Department of Oncology, Lombardi Comprehensive Cancer Center, Georgetown University Medical Center, 3970 Reservoir Road, Washington, DC20057, USA

+ Contributed equally

Full list of author information is available at the end of the article uncleaved precursor protein with a predicted molecular weight of $\sim 290 \mathrm{kD}$. MLL2 ${ }^{\mathrm{FL}}$ precursor protein undergoes post-translational proteolytic maturation, which is critical to its normal biological activity [2]. The enzyme responsible for MLL2 cleavage is taspase 1, and its consensus cleavage site (D/GVDD) is at a.a. 2063 [2]. Proteolytic cleavage generates a large $\mathrm{N}$-terminus fragment with a predicted molecular weight of $215 \mathrm{kD}$, and a smaller C-terminus fragment which separates at $\sim 75 \mathrm{kD}$ in a denaturing gel. The cleaved fragments subsequently associate to generate a stable, functional, noncovalent heterodimeric complex [2]. 
The SET domain of MLL2 possesses histone H3 lysine 4 (H3K4) methyltransferase activity, and is an important component of the multi-protein complex involved in epigenetic gene regulation and embryonic development [35]. For example, in vitro, MLL2 complex has been shown to associate with Pax7, a transcription factor, and activate myogenic genes through $\mathrm{H} 3 \mathrm{~K} 4$ methylation [4]. In vivo, Mll2 is shown to be required for normal embryonic development in mice [5-7]. A survey of the literature shows that several proteins with a primary function in epigenetic regulation and/or embryonic development are often aberrantly expressed in cancer. This finding is related to the observation that embryonic development and tumorigenesis share several common pathways [8]. Furthermore, proteins with chromatin remodeling motifs, such as PHD zinc fingers and SET domains, are often aberrantly expressed in tumors [9-11]. Considering all these features of MLL2, along with its significant structural similarity to MLL, we suspected that the MLL2 gene or its product may be altered in cancer, similar to it's paralog MLL, which is directly linked to haematopoietic tumorigenesis [12]. A literature survey, however, found only one published report describing $M L L 2$ amplification through complex chromosomal rearrangements and duplications in human cancer cell lines [13]. Querying ONCOMINE, a publicly available source of gene expression data sets in cancers [14], we identified a few studies which listed MLL2 as one of the deregulated genes in some cancers-including melanoma, bladder and lung carcinomas-when compared to the corresponding normal tissues [14]. Subsequently, tissue microarray based preliminary screening in our laboratory also indicated that MLL2 may be disrupted in certain cancers. We, therefore, decided to investigate MLL2 expression in breast and colon cancer cell lines, and then substantiated our findings in archived formalin fixed paraffin embedded (FFPE) tumor tissues from patients with confirmed diagnoses of breast and colon cancers.

In order to study MLL2 in breast cancer cells, we selected a panel of six breast epithelial cell lines representing non-tumor breast epithelial derived cell lines (184A1 and MCF 10A) [15], weakly invasive breast tumor cell lines (T47D and MCF 7) $[15,16]$ and highly invasive breast tumor cell lines (MDA-MB-157 and MDA-MB231) [16]. For investigating MLL2 in colon cancer cells, we selected three cell lines derived from well-differentiated colon carcinomas (HT29, DLD-1 and Ls174T) [17$19]$ and three from poorly differentiated colon carcinomas (Lovo, Colo 205 and SW 480) [18,20,21]. We then substantiated our observations in cell lines by investigating MLL2 levels in breast and colon cancer tissues. Here we report that MLL2 expression is disrupted in invasive tumor cell lines and invasive carcinomas.

\section{Results}

MLL2 in breast cancer cell lines

MLL2 protein levels are elevated and MLL2 is incompletely processed in highly invasive breast cancer cell lines

Human mammary cell lines--184A1, MCF10A, T47D, MCF7, MDA-MB-157 and MDA-MB-231--were processed to obtain nuclear and cytoplasmic extracts. Analysis of the extracts revealed the presence of a $75 \mathrm{kD}$ fragment corresponding to the cleaved C-terminal segment of MLL2 in the nuclear and/or cytoplasmic fractions (Fig. 1A). The nuclear $75 \mathrm{kD}$ signal was strongest in MCF10 a and weakest in MDA-MB-231 and 184A1, while the cytoplasmic $75 \mathrm{kD}$ signals were very intense in the more malignant cell lines (Table 1). Besides the $75 \mathrm{kD}$ signal, in the cytoplasmic fractions of MCF7, MDA-MB-157 and MDA-MB-231, and the nuclear fractions of MDAMB-157 and MDA-MB-231 cell lines, an additional signal was observed at $\sim 290 \mathrm{kD}$, corresponding to the MLL2 ${ }^{\mathrm{FL}}$ (Table 1). The $\sim 290 \mathrm{kD}$ signal was either absent or faint in the nuclear and cytoplasmic fractions of 184A1, MCF10A and T47D (Fig 1A). Overall, MLL2 protein levels increased with increasing malignant potential of the cell lines.

MLL2 transcript levels are increased in cell lines derived from invasive tumors

Examination of MLL2 RNA levels by semi quantitative reverse transcription polymerase chain reaction (RTPCR) in the mammary epithelial cell lines revealed highest levels of MLL2 transcript in MDA-MB-231 and least in 184A1 (Fig 1B). A gradual increase in the MLL2 RNA levels was observed in the order of 184A1, MCF10a, T47D, MCF7, MDA-MB-157 and MDA-MB-231.

\section{Taspase 1 levels and its putative MLL2 cleavage site are not} altered

Examination of endogenous taspase 1 (enzyme responsible for proteolytic processing of MLL2) protein levels, revealed bands of consistent intensities in the cytoplasmic fractions of the breast cell lines used in this study (Fig 1A). Additionally, analyses of the MLL2 sequences coding for the taspase 1 cleavage site showed no alterations in cell lines carrying MLL2 ${ }^{\mathrm{FL}}$ (data not shown).

\section{MLL2 in colon cancer cell lines MLL2 protein is elevated and incompletely processed in poorly differentiated colon cancer cell lines}

Established cell lines from colon cancer tissues--HT29, DLD-1, Ls174T, Lovo, Colo205 and SW480--were processed to obtain nuclear and cytoplasmic extracts. Analysis of these nuclear-cytoplasmic extracts revealed a $75 \mathrm{kD}$ signal corresponding to the cleaved, C-terminal peptide of MLL2 in the nuclear and/or cytoplasmic fractions (Fig 1C, Table 2). The $75 \mathrm{kD}$ band was most intense in the nuclear fractions of HT-29, DLD-1, Ls174T and Lovo, and least in Colo205 and SW480. In the cytoplasmic frac- 
Table 1: Relative levels of MLL2 protein in mammary epithelial cell lines

\begin{tabular}{|c|c|c|c|c|c|}
\hline \multirow[t]{3}{*}{ Cell lines } & \multirow{3}{*}{$\begin{array}{l}\text { Origin, } \\
\text { Description, ER } \\
\text { status }\end{array}$} & \multicolumn{2}{|c|}{ Nuclear MLL2 } & \multicolumn{2}{|c|}{ Cytoplasmic MLL2 } \\
\hline & & 75 kD & 290 kD & 75 kD & 290 kD \\
\hline & & (Cleaved) & (Uncleaved) & (Cleaved) & (Uncleaved) \\
\hline 184A1 & $\begin{array}{l}\text { Normal breast } \\
\text { epithelium, } \\
\text { immortalized, ER - }\end{array}$ & + & - & + & - \\
\hline MCF 10a & $\begin{array}{l}\text { Normal breast } \\
\text { epithelium, } \\
\text { immortalized, ER- }\end{array}$ & +++ & - & ++ & - \\
\hline T47D & $\begin{array}{l}\text { Early stage breast } \\
\text { carcinoma, } \\
\text { tumorigenic, non- } \\
\text { metastatic, ER + }\end{array}$ & ++ & - & +++ & - \\
\hline MCF7 & $\begin{array}{l}\text { Early stage breast } \\
\text { carcinoma, } \\
\text { tumorigenic, non- } \\
\text { metastatic, ER + }\end{array}$ & ++ & - & + & ++ \\
\hline MDA-MB-157 & $\begin{array}{l}\text { Advanced breast } \\
\text { carcinoma, } \\
\text { Tumorigenic and } \\
\text { metastatic, ER - }\end{array}$ & + & ++++ & +++ & +++ \\
\hline MDA-MB-231 & $\begin{array}{l}\text { Advanced breast } \\
\text { carcinoma, } \\
\text { Tumorigenic and } \\
\text { metastatic, ER - }\end{array}$ & + & ++++ & +++ & +++ \\
\hline
\end{tabular}

tions, the cleaved MLL2 appeared in all cell lines except HT29 and DLD-1. Additionally, Colo205 and SW480 displayed abundant levels of uncleaved MLL2 ${ }^{\mathrm{FL}}$ (Table 2) in nuclear fractions compared to the cytoplasmic fractions (Fig 1C).

MLL2 RNA levels are increased in cell lines derived from poorly differentiated colonic tumors

MLL2 RNA levels were found to be higher in the colon cell lines -- Lovo, Colo205 and SW480-compared to HT29, DLD-1 and Ls174T (Fig 1D).

Taspase 1 levels and putative cleavage sites are not altered in colon cancer cell lines

Immunoblots of the cell line derived fractions were probed with anti-taspase 1 antibody, which revealed variable amounts of taspase 1 in the cytoplasmic fractions of the colonic cell lines examined (Fig 1C). DNA sequence analyses using primers flanking the coding sites for taspase 1 cleavage site in the $M L L 2$ gene revealed no alterations in the colonic cancer cell lines carrying MLL2 ${ }^{\mathrm{FL}}$ (data not shown).

MLL2 expression measured by immunohistochemistry, in breast tumor and normal adjacent tissues

Patient demography

The results presented in this study originated from ninety-six female patients with breast carcinoma, ranging in age from 26 to 89 years, with a mean age of 59 years at the time of diagnosis. Lymph node (LN) status was available for 95 (99\%) cases. Tumor size was available for 90 $(94 \%)$ cases and tumor grades were available for $68(71 \%)$ 


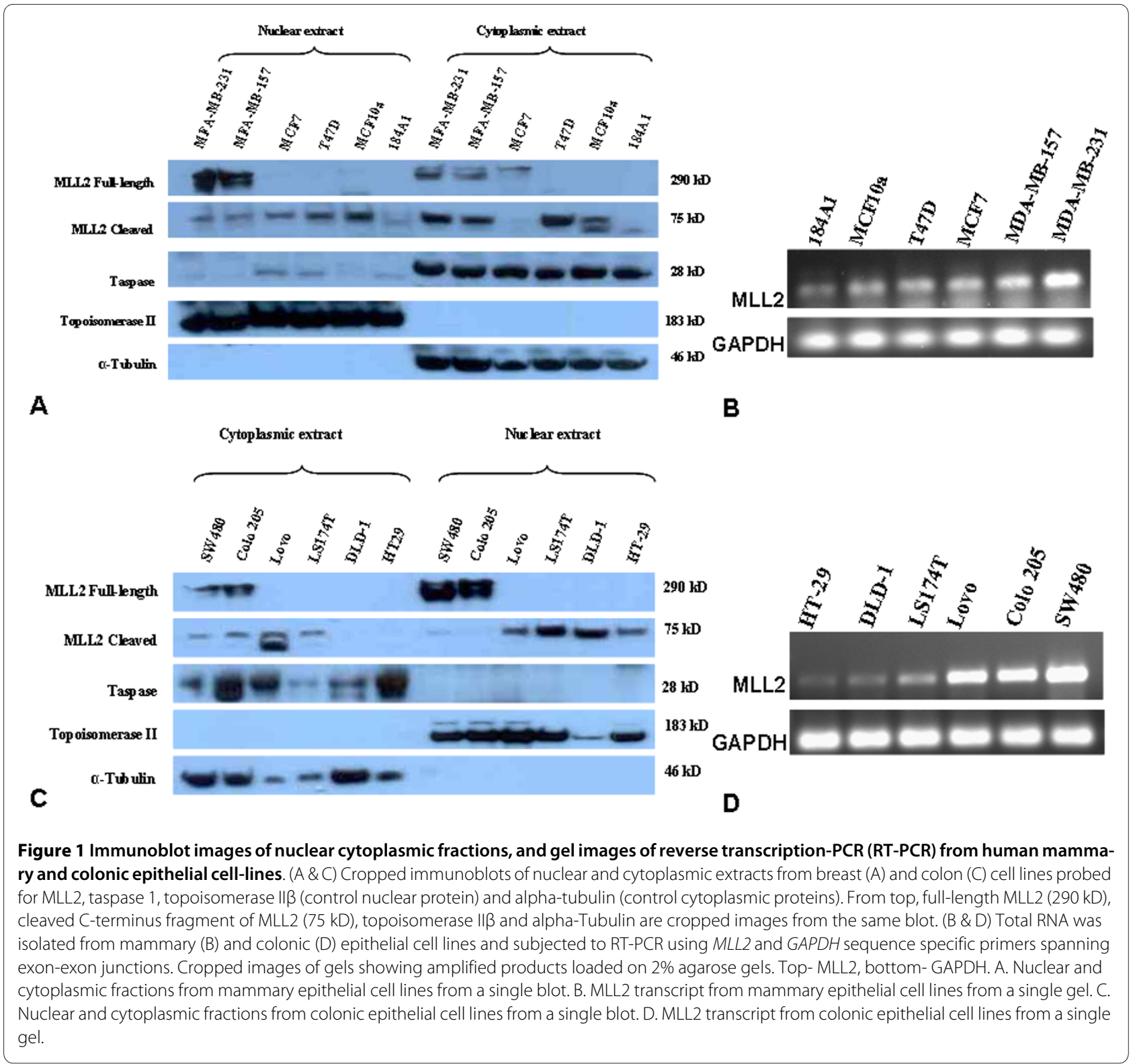

cases. Estrogen receptor (ER) and progesterone receptor (PR) status was known for 88 (92\%) and $77(80 \%)$ cases, respectively. HER-2/neu status was available for 87 (91\%) cases. Overall survival status was known for all, and recurrence data was available for 95 (99\%) cases.

Tumor and benign tissues were present in all $(100 \%)$ cases with invasive carcinoma (IC) of the breast. Sixtythree $(66 \%)$ were ductal and $33(34 \%)$ were lobular carcinomas. LN status was positive in 50/95 (55\%), and negative in $41 / 95(45 \%)$ cases. Tumor size was $\leq 2 \mathrm{~cm}$ for $36 /$ 90 (40\%), and $>2 \mathrm{~cm}$ for $54 / 90(60 \%)$ cases. Of the sixtyeight graded tumors, 18 (26\%) were well differentiated, 33 $(49 \%)$ moderately differentiated, and 17 (25\%) poorly differentiated. There were $81 / 96(84 \%)$ early stage ( 1 and 2 ), and $15 / 96$ (16\%) advanced stage (3 and 4 ) tumors. ER was positive in $64 / 88$ (73\%) cases while PR in $43 / 77$ (56\%) cases, and 21/87 (24\%) cases were HER2/neu positive. Thirty-seven (38\%) cases had post-surgical disease recurrence, and 59/96 (62\%) had expired.

\section{Immunohistochemically detected MLL2 expression was} significantly elevated in tumor tissues compared to adjacent benign tissue

Cytoplasmic MLL2 immunostaining was increased (Fig. 2A, Table 3) in the malignant tissues in 86/96 (90\%) cases $(\mathrm{p}<0.05)$ compared to benign epithelium from the same patients (Fig 2B). Cytoplasmic expression correlated with early tumor stage $(\mathrm{p}=0.02)$, and menopausal status $(\mathrm{p}=$ 0.03 ) (Table 4). Nuclear immunoreactivity was observed in 43/96 (45\%) cases (Fig. 2C) and did not correlate with 
Table 2: Relative levels of MLL2 protein in colonic cell lines

\begin{tabular}{|c|c|c|c|c|}
\hline \multirow[t]{3}{*}{ Cell lines } & \multicolumn{2}{|c|}{ Nuclear MLL2 } & \multicolumn{2}{|c|}{ Cytoplasmic MLL2 } \\
\hline & 75 kD & 290 kD & 75 kD & 290 kD \\
\hline & (Cleaved) & (Uncleaved) & (Cleaved) & (Uncleaved) \\
\hline HT29 & + & - & - & - \\
\hline DLD-1 & ++ & - & - & - \\
\hline Ls174T & ++ & - & + & - \\
\hline Lovo & + & - & ++ & - \\
\hline Colo205 & - & ++++ & + & ++ \\
\hline SW480 & - & ++++ & + & ++ \\
\hline
\end{tabular}

Distribution of cleaved and uncleaved MLL2 protein in nuclear and cytoplasmic fractions of colon carcinoma cell lines

Staining intensity - Negative; + Weak; +++ Moderate, ++++ Intense

any of the clinicopathologic variables. Distribution pattern for nuclear immunoreactivity is detailed in Table 3.

MLL2 expression by immunohistochemistry, in tumor and adjacent normal tissues of the colon

\section{Patient demography}

Sixty-six patients, including 34 (52\%) males and 32 (48\%) females, who had invasive carcinoma of the colon were included in this study. The patients ranged in age from 38 to 92 years, with a mean age of 70 years at diagnosis. Tumor and benign tissue were present in all 66 cases with IC of the colon. LN status was positive in $32 / 66$ (49\%) cases, and negative in 34/66 (51\%) cases. There were 4/66 (6\%) well differentiated, 54/66 (82\%) moderately differentiated, and $8 / 66(12 \%)$ poorly differentiated tumors. There were $18 / 66$ (27\%) early stage ( 1 and 2 ), and 48/66
(73\%) advanced stage (3 and 4) tumors. Survival status was available for all cases and 50/66 (76\%) patients had expired.

Immunohistochemically detected MLL2 expression is significantly elevated in tumor tissues compared to adjacent benign mucosa

Cytoplasmic MLL2 immunostaining was significantly increased in 63/66 (95\%) tumors ( $\mathrm{p}<0.05$ ) when compared to adjacent benign mucosa (Fig 3A, Table 5). No correlation was observed between cytoplasmic MLL2 expression and any of the clinicopathologic variables. Nuclear staining was increased (Fig 3B) in 77\% cases (p < 0.05 ) (Table 5) compared to benign mucosa from the same cases (Fig 3C). Increased nuclear MLL2 expression correlated with early stage tumors $(\mathrm{p}=0.03)$ (Table 6) and absence of LN involvement ( $\mathrm{p}=0.005)$ (Table 6).

Table 3: Immunohistochemically detected MLL2 expression in human breast tissue ( $\mathbf{n}=96)$

\begin{tabular}{ccc}
\hline & Nuclear MLL2 staining \\
\hline Positive staining & $43 / 96(45 \%)$ \\
\hline Tumor vs. Benign & $17 / 43(39 \%)$ \\
\hline$T<B$ & $8 / 96(100 \%)$ \\
\hline$T=B$ & $1 / 96(1 \%)$ \\
\hline$T>B$ & $18 / 43(42 \%)$ \\
\hline
\end{tabular}


Table 4: MLL2 expression and clinicopathological variables in breast cancer $(n=96)$

\begin{tabular}{|c|c|c|}
\hline & $\begin{array}{l}\text { Number of cases positive for } \\
\text { cytoplasmic MLL2 }\end{array}$ & $\begin{array}{c}\text { Number of positive cases where } \mathrm{T}>\mathrm{B} \\
\text { (\%) }\end{array}$ \\
\hline $\mathbf{N}$ & 96 & $86(90)$ \\
\hline \multicolumn{3}{|l|}{ Tumor stage } \\
\hline Early (1 \& 2) & 81 & $75(93)^{*}$ \\
\hline Advanced (3 \& 4) & 15 & $11(73)$ \\
\hline \multicolumn{3}{|l|}{ Menopausal status } \\
\hline Pre & 20 & $16(80)$ \\
\hline Post & 76 & $70(92)^{* *}$ \\
\hline
\end{tabular}

\section{Discussion}

In the present study we observed that: (a) MLL2, primarily regarded as a nuclear protein with nuclear localization signals, displayed significant cytoplasmic localization in both normal and malignant cells, (b) mammary and colonic cell lines derived from highly invasive tumors exhibited altered sub-cellular distribution and proteolytic processing of MLL2 compared to non-tumor/less-inva-

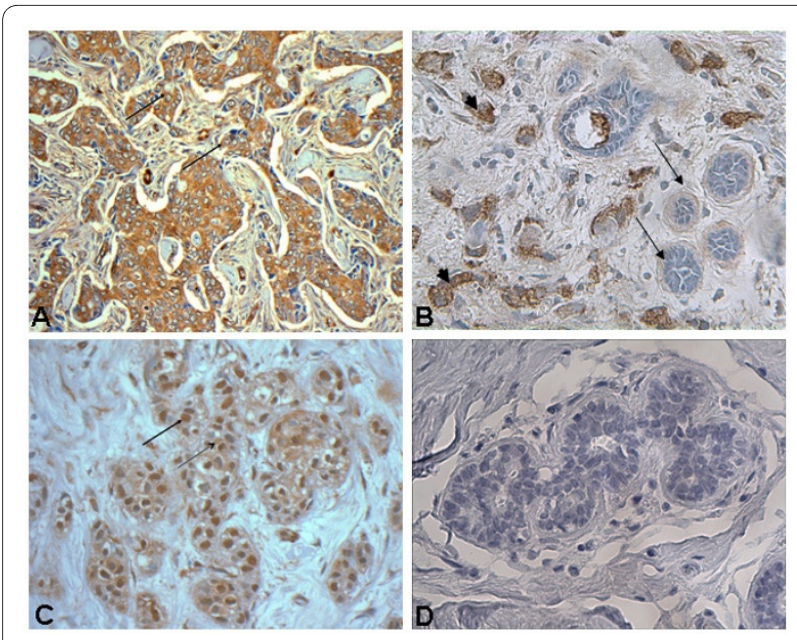

Figure 2 Representative immunohistochemistry staining for MLL2 in human FFPE breast tissue sections A. Intense cytoplasmic MLL2 immunostaining in epithelial cells (arrows) of tissue section from invasive breast carcinoma, $\times 400$. B. Breast tissue showing strong cytoplasmic immunoreactivity of MLL2 in invasive ductal carcinoma (solid arrow head) cells compared to the adjacent, benign (arrows) mammary ducts, $\times 200$. C. Strongly positive nuclear (arrow) MLL2 immunostaining in epithelial cells of invasive breast carcinoma tissue section, $\times 400$. D. Negative control, $\times 400$ sive-tumor cell lines, and (c) MLL2 is overexpressed in breast and colon tumors tissues compared to the corresponding normal adjacent tissues.

MLL2 is primarily regarded as a nuclear protein. However, we observed both nuclear and cytoplasmic MLL2 in cell lines and tissue sections from breast and colon. In the breast epithelial cell lines, MLL2 specific bands representing the cleaved $(75 \mathrm{kD})$ protein were observed in the cytoplasmic fractions of not only the tumor cell lines but also the non-tumor cell lines, 184A1 and MCF10a (Fig 1A); while bands representing the full-length, unprocessed MLL2 $(290 \mathrm{kD})$ were present in the highly invasive tumor cell lines alone, and which may be related to oncogenic activity. The nuclear-cytoplasmic localization pattern of MLL2 was also evident in the benign sections of both breast and colonic tissues, but it was not possible to delineate the cleaved from the uncleaved MLL2 as the antibody used in this study cannot differentiate one from the other in situ (details of antibody specificity are described in Methods section). Considering this cytoplasmic presence of MLL2 in the non-tumor cell lines and non-tumor tissue sections, it is possible that MLL2 may have a yet unidentified function in the cytoplasm, besides its role in epigenetic regulation in the nucleus $[22,23]$. However, a notably increased cytoplasmic presence in the cancer cell lines and cancer tissues, together with the presence of MLL2 ${ }^{\mathrm{FL}}$ could be a tumor-related anomaly resulting from overexpression or increased protein/RNA stability.

Our study of the breast and colonic cell lines revealed two notable trends related to the proteolytic processing of MLL2. First, we observed a gradient in the intensities 
Table 5: Immunohistochemically detected MLL2 expression in human colonic tissues

\begin{tabular}{lcc}
\hline & Nuclear MLL2 staining & Cytoplasmic MLL2 staining \\
\hline Positive cases & $35 / 66(53 \%)$ & $66 / 66(100 \%)$ \\
\hline Tumor vs. Benign & & $3 / 66(5 \%)$ \\
\hline$T<B$ & $7 / 35(20 \%)$ & $0 / 66(0 \%)$ \\
\hline$T=B$ & $1 / 35(3 \%)$ & $63 / 66(95 \%)^{*}$ \\
\hline$T>B$ & $27 / 35(77 \%)^{*}$ & \\
\hline Distribution of colon cancer cases based on nuclear and cytoplasmic MLL2 immunostaining in tumor versus benign tissue; ${ }^{*} p<0.05$
\end{tabular}

of the $75 \mathrm{kD}$ signal in the nuclear fractions of both breast and colonic cell lines (Fig. 1A \&1C). In the breast epithelial cell lines, the intensities of the $75 \mathrm{kD}$ nuclear MLL2, indicative of normal proteolytic processing, showed a decreasing trend with increasing malignancy from MCF10A to MDA-MB-231 except for MCF7. Of these cell lines, 184A1 and MCF10A are non-tumorigenic, MCF7 [16] and T47D are tumorigenic [15] but weakly invasive [24], while MDA-MB-157 and MDA-MB-231 [16] are highly invasive $[15,24,25]$. The non-tumor cell line, 184A1, did not fit this trend and this discrepancy could be attributed to an overall lower level of MLL2 in $184 \mathrm{~A} 1$, and/or the difference in proliferation rate--184A1 cells are reported to have a relatively lower proliferation rate compared to MCF10A [25]. In the colonic epithelial cell lines a similar intensity gradient was noted for the 75 $\mathrm{kD}$ nuclear MLL2 fragment. Of these cell lines, HT29
[17], DLD-1 [18] and Ls174T [19] are derived from welldifferentiated tumors while, Lovo [18], Colo205 [20] and SW480 [21] are derived from poorly differentiated tumors; and the $75 \mathrm{kD}$ nuclear MLL2 was least in the Colo205 and SW480 cell lines.

The second notable trend was the presence of an additional band of $290 \mathrm{kD}$ size (corresponding to the uncleaved precursor MLL2 ${ }^{\mathrm{FL}}$ ) in the more invasive/ poorly differentiated cell lines. More importantly, the MLL2 ${ }^{\mathrm{FL}}(290 \mathrm{kD})$ signal intensity increased in the nuclear and cytoplasmic fractions as the $75 \mathrm{kD}$ nuclear signal decreased (Fig. 1A \&1C). This uncleaved MLL2 ${ }^{\mathrm{FL}}$ observed in the cytoplasmic and nuclear fractions of the advanced tumor cell lines could be a consequence of insufficient endogenous taspase 1 required for processing the excess MLL2. Since proteolytic cleavage could also be impaired as a consequence of non-cleavable mutations in

Table 6: MLL2 expression and clinicopathological variables in breast cancer $(n=96)$

\begin{tabular}{lcc}
\hline & $\begin{array}{c}\text { Number of cases positive for nuclear } \\
\text { MLL2 }\end{array}$ & Number of positive cases where T $>$ B \\
(\%) & 27 (77) \\
\hline Lymph node & $\mathbf{3 5}$ & $19(95)^{* * *}$ \\
\hline Negative & 20 & $8(53)$ \\
\hline Positive & 15 & $11(92)^{* *}$ \\
\hline Tumor stage & & $16(70)$ \\
\hline Early & 12 & \\
\hline Advanced & 23 & \\
\hline
\end{tabular}

Clinicopathological variables associated with elevated levels of nuclear MLL2 immunoreactivity in patients with invasive colon carcinoma; ${ }^{* *} p=0.03 ;{ }^{* * *} p=0.005$ 


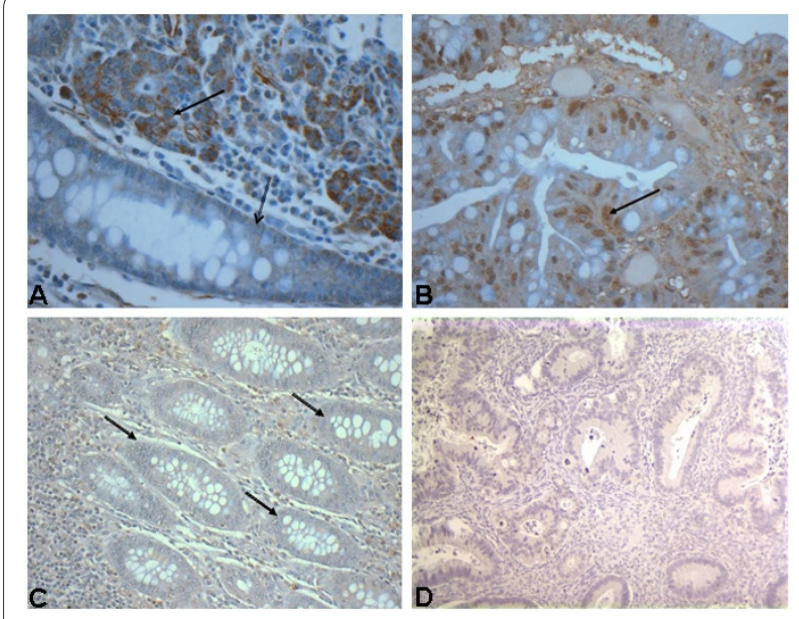

Figure 3 Representative immunohistochemistry staining for MLL2 in human FFPE colonic tissue sections. A. Note differential cytoplasmic MLL2 immunostaining in tissue section from invasive carcinoma of the colon (solid arrow) and adjacent normal mucosa (hollow arrow), $\times 400$. B. Nuclear immunoreactivity of MLL2 (arrow) in invasive colon carcinoma, $\times 400$ C. Weakly positive MLL2 immunostaining in adjacent benign colonic epithelial cells (arrows), $\times 200$ from same patient whose tumor sample is shown in (B) D. Anti-MLL2 antibody was incubated with blocking peptide and added to the slide with FFPE colon tissue, followed by washing and staining with secondary antibody and visualization by using diaminobenzidine (DAB) as a precipitating enzyme product.

$\mathrm{MLL}^{\mathrm{FL}}$ or the absence/decrease in the endogenous taspase 1 that cleaves MLL2 [2], we looked for mutations in the $M L L 2$ sequence coding for taspase 1 cleavage site, and also examined taspase 1 protein levels in the cell lines. Sequence analysis of the coding region for taspase 1 cleavage sites in cell lines carrying MLL2 ${ }^{\mathrm{FL}}$ did not reveal any alterations in the cleavage site encoding sequences. In addition, we found that the taspase 1 protein levels did not vary in parallel with the presence or absence of MLL2 ${ }^{\mathrm{FL}}$. Taspase 1 protein levels were consistent across the six breast tissue cell lines, irrespective of the presence of MLL2 ${ }^{\mathrm{FL}}$. Although we did not observe consistent levels of taspase 1 across the colonic cell lines, we did observe that the presence or absence of MLL2 ${ }^{\mathrm{FL}}$ and its levels, failed to correlate with taspase 1 level. That is, higher levels of taspase 1 did not correspondingly correlate with decreased levels of MLL2 ${ }^{\mathrm{FL}}$ or its total absence. These results suggest that the presence of MLL2 ${ }^{\mathrm{FL}}$ in the invasive cell lines is not a consequence of diminished levels of taspase 1 or a mutated cleavage site in the MLL2. Further investigation is required, to determine the cause and consequences of MLL2 ${ }^{\mathrm{FL}}$ in the nucleus, which might be related to the shift in the nuclear-cytoplasmic localization of MLL2 in the invasive cell lines. Whatever may be the cause, our results suggest that the presence of precursor MLL2 ${ }^{\mathrm{FL}}$ is associated with a higher degree of malignancy.
According to an earlier report [2], proteolytic processing of MLL2 ${ }^{\mathrm{FL}}$ is crucial to its stability, sub-nuclear localization, and methyltransferase activity. Impaired proteolytic maturation could result in significant changes in the normal epigenetic regulatory activities of MLL2. It has been shown in vitro that MLL2 forms a multiprotein complex with Wdr5-Ash2L [26] and associates with proteins like Pax7 and NF-E2 to direct histone lysine methylation at specific gene loci $[3,4]$. MLL2 specific histone methylation complex is also known to associate with the tumor suppressor protein, menin, and mediate histone methylation at Hoxc8 locus [27]. Given the critical role for MLL2 in histone methylation activities, we believe that proteolytically immature and/or inappropriately expressed MLL2 may fail to effectively associate with the other members of the histone-methyltransferase complex, which in turn can adversely affect its role in epigenetic gene regulation.

In our analysis of the breast and colonic cell lines by reverse transcription (RT)-PCR, we also observed that MLL2 RNA levels were highest in the invasive tumor cell lines and least in the non-tumor/less-invasive-tumor cell lines (Fig. 1B \&1D). This trend in the MLL2 RNA levels was consistent with our observation of the overall increase in protein levels in the invasive tumor cell lines and in the tumor tissues. Since a real-time measurement was not performed on these cell lines it is not known if the increased levels of RNA resulted from an increased rate of transcription. The observed gradient in RNA levels in the breast and colon cell lines could also be due to differences in RNA stability. Though the RT-PCR results are not strictly quantitative, the results do indicate that MLL2 RNA levels are more abundant in the highly invasive/less differentiated cell lines.

Finally, our study on tissue sections from breast and colon cancer patients revealed that immunohistochemically detected MLL2 is significantly increased in tumor tissues. In breast tumors from patient samples, cytoplasmic MLL2 was significantly overexpressed as compared to normal adjacent tissues, and in colon tumors both cytoplasmic and nuclear MLL2 were significantly overexpressed when compared to adjacent benign mucosa. Since immunohistochemical signals can often arise from non-specific antibody reactions, we evaluated the specificity of antibody reactivity using a blocking peptide, a part of which represented the epitope recognized by antiMLL2 antibody (detailed in Methods section). The peptide blocks the ability of the antibody to bind to its antigen. These experiments confirmed a high specificity of the antibody to the MLL2 antigen (Fig. 3D).

Analysis of MLL2 expression data with clinicopathological variables revealed a small correlation between MLL2 overexpression and early tumor stages (breast and colon) and absence of lymph node involvement (colon). How- 
ever, the number of cases in each category was too small and the association too tentative to draw a substantive conclusion at this juncture. Despite a lack of correlation with established clinicopathological variables, the elevated levels of MLL2 protein in both breast and colon cancer was significant. These results are in line with our observation of increased MLL2 protein and RNA levels in the cell lines. However, due to the lack of an appropriate antibody to distinguish the cleaved MLL2 from uncleaved MLL2 ${ }^{\mathrm{FL}}$ by immunohistochemistry, we cannot comment on the composition of the overexpressed protein as to whether it constituted more of the $75 \mathrm{kD}$ fragment or the $290 \mathrm{kD} \mathrm{MLL2}{ }^{\mathrm{FL}}$. The elevated levels of MLL2 in the tumor tissues could be the result of overexpression, genomic amplification, increased RNA and/or protein stability, or, at least in part, due to alterations in protein processing. For example, genomic amplification of $M L L 2$ (through complex chromosomal rearrangements or chromosomal duplications) resulting in four $M L L 2$ copies has been previously reported in one of the breast cancer cell line, MDA-MB-157, used in this study [13].

Whichever may be the cause, deregulated expression of MLL2 and/or defective proteolytic processing may adversely impact MLL2 mediated histone methylation activities, and in turn, disrupt downstream target genes potentially involved in cell cycle or cell proliferation activities. Consequently, aberrantly expressed MLL2 driven epigenetic regulation may contribute to tumor growth and/or progression. If such is the case, deregulation of MLL2 may be a more generic feature in tumorigenesis rather than an event specific to a particular tumor type, as is indicated by our findings in both breast and colon tumors.

\section{Conclusions}

In all, our study shows for the first time that overexpression of MLL2, an altered subcellular distribution, and aberrant proteolytic processing may be linked to tumorigenesis in mammary and colonic tissues. This linkage may be attributed, at least in part, to the role of MLL2 in histone methyltransferase activities [22,23]. Given the well-known role for MLL in leukemias, and the increasing focus on abnormal epigenetic regulation in cancer, the results of this study present a strong argument for further investigation of MLL2 and its possible involvement in solid tumors.

\section{Methods}

Cell lines, nuclear-cytoplasmic fractionation, immunoblotting

\section{Cell lines}

All parental cell lines were initially purchased from American Type Culture Collection (ATCC) and maintained at the University's Tissue Culture Core facility.
Human breast epithelial cell lines used in this study included 184A1, MCF10A, T47D, MCF7, MDA-MB-157 and MDA-MB-231. MCF10A and 184A1, are immortalized human mammary epithelial cell lines derived from non-tumor breast tissue $[15,16]$. T47D and MCF7 are $\mathrm{ER}+$, tumorigenic, non-metastatic, anti-estrogen sensitive cell lines. MDA-MB-157 and MDA-MB-231 are ER-, tumorigenic, metastatic and anti-estrogen resistant cell line.

The colonic epithelial cell lines used in this study included HT29, DLD-1, Ls174T, Lovo, Colo205 and SW480, and were initially obtained from ATCC and maintained at the Tissue Culture Core facility of the University. HT29 [17], DLD1 [18] and Ls174T [19] were established from well differentiated carcinomas while Lovo [18], Colo205 [20] and SW480 [21] were derived from poorly differentiated colon carcinomas.

Cell lines were maintained at $37^{\circ} \mathrm{C}$, in a humidified chamber with $5 \% \mathrm{CO}_{2}$, in $\mathrm{T}-175 \mathrm{~cm}^{2}$ tissue culture flasks. MCF10A was grown in a 1:1 mixture of Ham's-F12 medium and DMEM (Gibco, USA), with $2.5 \mathrm{mM}$ L-glutamine, and supplemented with $20 \mathrm{ng} / \mathrm{ml}$ epidermal growth factor, $0.01 \mathrm{mg} / \mathrm{ml}$ insulin, $500 \mathrm{ng} / \mathrm{ml}$ hydrocortisone, and $5 \%$ horse serum. Cell line $184 \mathrm{~A} 1$, was grown in MEGM $^{\circ}$ (Clonetics ${ }^{\circ}$ ) complete media (10 ng/ml hEGF, 5 $\mathrm{ug} / \mathrm{ml}$ insulin, $0 / 5 \mathrm{ug} / \mathrm{ml}$ hydrocortisone and bovine pituitary extract). All other breast cell lines were cultured in DMEM complete media containing $4.5 \mathrm{~g} / \mathrm{L}$ glucose, 2 $\mathrm{mM}$ L-glutamine, $1 \mathrm{mM}$ sodium pyruvate, $0.1 \mathrm{mM}$ nonessential amino-acids, and supplemented with $5 \%$ fetal bovine serum (FBS). The colonic epithelial cell lines HT29, Ls174T and SW480 were grown in DMEM complete media. DLD-1 and Colo205 were cultured in RPMI 1640 media supplemented with $10 \%$ FBS, $1 \%$ Sodium pyruvate and $1 \%$ non-essential amino acids. Lovo was cultured in Ham's F12K media supplemented with 10\% FBS.

\section{Nuclear-Cytoplasmic fractionation}

Equal volumes of the cell pellet from each cell line were used for fractionation following an established protocol [28]. Known volumes of cell pellets were resuspended in a hypotonic buffer (HB) (10 mM Tris pH 7.9, $1.5 \mathrm{mM}$ $\mathrm{MgCl}_{2}, 10 \mathrm{mM} \mathrm{KCl}, 20 \%$ TritonX-100 and protease inhibitors (Roche, Germany)), and incubated on ice for 30 minutes with vortexing for $30 \mathrm{~s}$ at intervals of 10 minutes. The suspension was then centrifuged at $1000 \mathrm{~g}$, pellets were saved, and the supernatant was centrifuged at 7000 r.p.m. in a fresh tube to remove debris. To the supernatant, $5 \mathrm{M} \mathrm{NaCl}$ was added to achieve a final concentration of $200 \mathrm{mM}$ cytoplasmic extract. The saved pellet was resuspended in high salt concentration buffer $\mathrm{C}(10 \mathrm{mM}$ Tris pH 7.9, $1.5 \mathrm{mM} \mathrm{MgCl} 2,10 \mathrm{mM} \mathrm{KCl,} 400 \mathrm{mM} \mathrm{NaCl}$, $0.4 \%$ TritonX-100 and protease inhibitors) and vortexed for 30 minutes at $4^{\circ} \mathrm{C}$, followed by centrifugation at $20,000 \mathrm{~g}$. The supernatant was transferred to a fresh tube 
and an equal volume of $\mathrm{HB}$ was added to achieve a final concentration of $200 \mathrm{mM} \mathrm{NaCl}$. This constituted the nuclear extract.

\section{Immunoblotting and antibodies}

Extracts were separated on a 3-8\% Tris-acetate denaturing gel (NuPAGE, Invitrogen, USA), and blotted onto a PVDF membrane. The blots were probed with anti-MLL2 (see Immunohistochemistry section for details) antibody (1:500) in 5\% non-fat dry milk dissolved in tris-buffered saline with $0.1 \%$ Tween-20, followed by goat anti-rabbit peroxidase conjugated secondary antibody (Santa Cruz Biotechnology, USA). The blots were subsequently probed with anti-taspase 1 (Santa Cruz Biotechnology, USA) (1:200) followed by secondary antibody. As evidence of purity of the nuclear and cytoplasmic fractions, blots were probed with mouse monoclonal anti-Topoisomerase II $\beta$ (1:1000) (BD Biosciences, USA) and antialpha-tubulin (1:5000) (Sigma, USA), respectively. The signals were detected by incubating the membrane with ECL chemiluminescent substrate (Immobilon substrate, Millipore, USA) for 5 minutes and then exposing an X-ray film (Pierce, USA) for $30 \mathrm{~s}$.

\section{DNA isolation and sequencing}

DNA from cell lines were isolated and purified by spin column (Epicenter ${ }^{\circ}$ Biotechnologies, WI, USA). PCR was performed with primers designed to amplify genomic DNA sequences coding for the putative cleavage site for taspase 1 . The primer sequences were- forward 5'-caggactgagtgctgctgac-3' and reverse 5'-agtatgatttggatgtggcg$g g t-3$ '. Amplified PCR products were purified by spin columns and sequenced at the University's core facility.

\section{RNA isolation and semi-quantitative reverse transcription- PCR}

Total RNA was extracted from cell lines using QIAzol lysis reagent (Qiagen, USA). Primers were designed spanning adjacent exon-exon junctions. Primer sequences were- forward 5'-tctcacggtgccaagatgg - 3 ' and reverse 5'tcggggcgctcgacctcgct -3'. GAPDH (control) primer sequences were- forward 5'-tgcaccaccaactgcttagc-3' and reverse 5'-ggcatggactgtggtcatgag-3'. To determine transcript levels of MLL2, one-step reverse transcriptasePCR (RT-PCR) was performed using equal amounts of total RNA from each cell line. Amplified products were separated on a $2 \%$ agarose gel containing ethidium bromide. Gels were imaged using FluorChem ${ }^{\text {тм }}$ IS-8900 imaging system, CA, USA (Alpha Innotech).

\section{Patients and Clinicopathology Mammary Carcinoma}

Formalin fixed paraffin embedded (FFPE) tissue sections from 96 patients who underwent either mastectomy or local excision for primary invasive mammary carcinoma, between 1983 and 1997, at the Albany Medical Center Hospital were randomly selected for the current study. This study was approved by the Albany Medical Center Institutional Review Board (IRB). The pathology and clinical records, tissue blocks, and hematoxylin and eosin stained slides were retrieved for each case. Slides were reviewed and samples were identified based upon the presence of adequate tumor tissue, the representative nature of the overall grade, and the presence of adjacent normal (non-tumor) epithelium. Tumor type, age at diagnosis, lymph node (LN) status, tumor size, tumor grade, pathologic stage, estrogen and progesterone steroid hormone receptor status, HER-2/neu status, recurrence, and overall survival were obtained by review of the medical records. Menopausal status was considered by defining premenopausal age as $\leq 55$ years, and postmenopausal age as $>55$ years. Tumors were graded using the modified Bloom and Richardson method [29]. This method is also the accepted standard for grading lobular carcinomas [29]. All cases were staged according to American Joint Committee on Cancer [30] criteria, using the TNM classification scheme, at the time of diagnosis. Estrogen/progesterone receptor (ER/PR) status was measured by competitive binding assays and immunohistochemistry (IHC). HER-2/neu protein status was detected by immunohistochemistry (IHC), or HER-2/neu gene amplification status measured by fluorescence in situ hybridization (FISH), or both.

\section{Colorectal Carcinoma}

FFPE tissue sections from 66 patients who underwent surgery for primary invasive colorectal carcinoma, between 1990 and 2000, at the Albany Medical Center Hospital, were randomly selected for the current study. This study was approved by the Albany Medical Center IRB. The pathology and clinical records, tissue blocks, and hematoxylin and eosin stained slides were retrieved for each case. Slides were reviewed and samples were identified based upon the presence of adequate tumor tissue, the representative nature of the overall grade, and the presence of adjacent benign epithelium. LN status was recorded for all cases. All tumors were graded and staged according to the Duke's system [31].

\section{Immunohistochemistry \\ MLL2 Immunostaining}

The anti-MLL2 polyclonal antibody [27] was purchased from Bethyl Labs, Inc., MD, USA (Cat \# A300-113A). This antibody is specific to an epitopic region upstream of the SET domain at the C-terminus, between residues 2375-2425. The antibody targets uncleaved MLL2 ${ }^{\mathrm{FL}}$ as well as cleaved fragments bearing the epitope. The C-terminus fragment resulting from natural proteolytic cleavage and processing of MLL2 ${ }^{\mathrm{FL}}$ is represented by a $75 \mathrm{kD}$ band in a denaturing gel immunoblot. The uncleaved 
MLL2 $^{\mathrm{FL}}$ has a predicted molecular weight of $290 \mathrm{kD}$. The specificity of the antibody to its target protein, MLL2, was confirmed by using MLL2 specific blocking peptide (Cat \# BP300-113, Bethyl labs, Inc., MD, USA) in IHC staining. A part of this blocking peptide represents a portion of the epitope recognized by the anti-MLL2 antibody. Anti-MLL2 antibody (1:30 dilution) was mixed with thirty-fold volumes of the blocking peptide at RT for $0.5 \mathrm{~h}$. This mixture was then added on to a slide with FFPE colon tissue section and incubated for $3 \mathrm{~h}$. The slide was then washed and stained with biotin conjugated secondary antibody, followed by the addition of streptavidin horseradish peroxidase (HRP) conjugate, and visualized by using diaminobenzidine (DAB) as a precipitating enzyme product (Fig. 3D). Other commercially available antibodies against MLL2 were tested, but not found to be suitable for this study.

Immunohistochemical staining for MLL2 in breast and colon tissue sections was performed on the Ventana ES automated IHC instrument (Ventana Medical Systems, Inc., Tucson, AZ) with an indirect biotin/avidin system (Ventana iVIEW detection). Four micron FFPE sections were cut from representative blocks of each case and transferred to glass slides. The tissue sections were dewaxed, rehydrated, and soaked briefly in wash buffer. Unmasking of the MLL2 antigenic determinant sites was not necessary. Immunostaining using anti-MLL2 was carried out at a dilution of $1: 30$, for $3 \mathrm{~h}$, at $37^{\circ} \mathrm{C}$. The specific antibody was localized using a biotin-conjugated secondary antibody $(1 \mathrm{~h})$, followed by the addition of a streptavidin horseradish peroxidase (HRP) conjugate. Immunoreactivity was visualized by utilizing $\mathrm{DAB}$ as a precipitating enzyme product. Finally, slides were counterstained with hematoxylin. To confirm specificity of primary antibody, negative control slides were run with every batch, using Ventana rabbit polyclonal negative control reagent. Images were acquired using Olympus BX51 (Tokyo, Japan) light microscope with Qimaging digital Camera (Tokyo, Japan) and Qcapture Pro51 software.

\section{Immunostaining Interpretation}

Cytoplasmic and nuclear MLL2 immunoreactivity was interpreted by a senior pathologist (B.V.S.K), without prior knowledge of the clinicopathology for each case of breast or colon carcinoma. Intensity and distribution were considered by semi quantitative assessment of the staining pattern. The staining intensity was scored as negative, weak (W), moderate $(\mathrm{M})$, or intense (I). The staining distribution was scored as focal $(\mathrm{F})(\leq 10 \%)$, regional (R) (11 - 50\%), or diffuse (D) ( $>50 \%)$. For analysis, intensity and distribution were given equal weight as a multiplicative index, obtained by multiplying intensity by distribution to obtain a total score. Each case was then assigned to one of three categories as follows: cases in which the total score for tumor was less than $(\mathrm{T}<\mathrm{B}$; decreased), equal to $(T=B)$, or greater than $(T>B$; increased) the adjacent benign tissue in the same case.

\section{Statistical analysis}

Statistical comparisons were carried out using the STATA software (Stata Corporation, College Station, TX). Chisquare test was used to determine significance of the associations between protein expression and prognostic variables. Multivariate analysis, including clinicopathologic parameters and expression of each targeted protein, was performed using the Cox proportional hazards model. The level of significance was set at $\mathrm{p}<0.05$.

\section{Abbreviations}

FBS: Fetal bovine serum; FFPE: Formalin fixed paraffin embedded; $\mathbf{H} 3 \mathbf{K} 4 \mathrm{me} 3$ Histone 3 Lysine 4 tri-methylation; HB: Hypotonic buffer; MLL2: Myeloid Lymphoid Leukemia 2; RT-PCR: Reverse transcription polymerase chain reaction; IHC: Immunohistochemistry.

\section{Competing interests}

The authors declare that they have no competing interests.

\section{Authors' contributions}

TGN conceived the study design, conducted in-vitro studies on cell lines, participated in immunohistochemical analysis and drafted the manuscript. BVK conducted histopathological reading of slides and their interpretations. CES performed the immunohistochemical staining and statistical analysis. MBB participated in the in-vitro experiments on cell lines. NG participated in primer design, optimization of immunohistochemical experiments and helped to draft the manuscript. AP participated in optimizing RT-PCR reactions. JSR provided critical comments for improving the manuscript. KTF was involved in study design, revising the manuscript critically for important intellectual content, and gave final approval of the version to be published. All authors read and approved the final manuscript.

\section{Acknowledgements}

We acknowledge Georgetown University Medical Center for financial support.

\section{Author Details}

1Department of Oncology, Lombardi Comprehensive Cancer Center, Georgetown University Medical Center, 3970 Reservoir Road, Washington, DC20057, USA, 2Department of Pathology, Georgetown University Medical Center, Washington, DC-20057, USA and ${ }^{3}$ Department of Pathology and Laboratory Medicine, Albany Medical College MC-81, 47 New Scotland Avenue, Albany, NY-12208, USA

Received: 8 January 2010 Accepted: 30 April 2010 Published: 30 April 2010

\section{References}

1. FitzGerald KT, Diaz MO: MLL2: A new mammalian member of the trx/ MLL family of genes. Genomics 1999, 59:187-192.

2. Takeda S, Chen DY, Westergard TD, Fisher JK, Rubens JA, Sasagawa S, Kan JT, Korsmeyer SJ, Cheng EH, Hsieh JJ: Proteolysis of MLL family proteins is essential for taspase-orchestrated cell cycle progression. Genes Dev 2006, 20:2397-2409.

3. Demers C, Chaturvedi CP, Ranish JA, Juban G, Lai P, Morle F, Aebersold R, Dilworth FJ, Groudine M, Brand M: Activator-mediated recruitment of the MLL2 methyltransferase complex to the beta-globin locus. Mol Cell 2007, 27:573-584

4. McKinnell IW, Ishibashi J, Le GF, Punch VG, Addicks GC, Greenblatt JF, Dilworth FJ, Rudnicki MA: Pax7 activates myogenic genes by recruitment of a histone methyltransferase complex. Nat Cell Biol 2008, 10:77-84.

5. Glaser S, Lubitz S, Loveland KL, Ohbo K, Robb L, Schwenk F, Seibler J, Roellig D, Kranz A, Anastassiadis K, Stewart AF: The histone 3 lysine 4 methyltransferase, MII2, is only required briefly in development and spermatogenesis. Epigenetics Chromatin 2009, 2:5. 
6. Glaser S, Schaft J, Lubitz S, Vintersten K, van der HF, Tufteland KR, Aasland R, Anastassiadis K, Ang SL, Stewart AF: Multiple epigenetic maintenance factors implicated by the loss of MII2 in mouse development 2. Development 2006, 133:1423-1432.

7. Lubitz S, Glaser S, Schaft J, Stewart AF, Anastassiadis K: Increased apoptosis and skewed differentiation in mouse embryonic stem cells lacking the histone methyltransferase MII2. Mol Biol Cell 2007, 18:2356-2366.

8. Kelleher FC, Fennelly D, Rafferty M: Common critical pathways in embryogenesis and cancer. Acta Oncol 2006, 45:375-388.

9. Schneider R, Bannister AJ, Kouzarides T: Unsafe SETs: histone lysine methyltransferases and cancer. Trends Biochem Sci 2002, 27:396-402.

10. Gong W, Suzuki K, Russell M, Riabowol K: Function of the ING family of PHD proteins in cancer. Int J Biochem Cell Biol 2005, 37:1054-1065.

11. Sims RJ III, Nishioka K, Reinberg D: Histone lysine methylation: a signature for chromatin function. Trends Genet 2003, 19:629-639.

12. Aplan PD: Chromosomal translocations involving the MLL gene: molecular mechanisms. DNA Repair (Amst) 2006, 5:1265-1272.

13. Huntsman DG, Chin SF, Muleris M, Batley SJ, Collins VP, Wiedemann LM, Aparicio S, Caldas C: MLL2, the second human homolog of the Drosophila trithorax gene, maps to $9 q 3$. and is amplified in solid tumor cell lines. Oncogene 1999, 18:7975-7984.

14. Rhodes DR, Yu J, Shanker K, Deshpande N, Varambally R, Ghosh D, Barrette T, Pandey A, Chinnaiyan AM: ONCOMINE: a cancer microarray database and integrated data-mining platform. Neoplasia 2004, 6:1-6.

15. Neve RM, Chin K, Fridlyand J, Yeh J, Baehner FL, Fevr T, Clark L, Bayani N, Coppe JP, Tong F, Speed T, Spellman PT, DeVries S, Lapuk A, Wang NJ, Kuo WL, Stilwell JL, Pinkel D, Albertson DG, Waldman FM, McCormick F, Dickson RB, Johnson MD, Lippman M, Ethier S, Gazdar A, Gray JW: A collection of breast cancer cell lines for the study of functionally distinct cancer subtypes. Cancer Cell 2006, 10:515-527.

16. Lacroix M, Haibe-Kains B, Hennuy B, Laes JF, Lallemand F, Gonze I, Cardoso F, Piccart M, Leclercq G, Sotiriou C: Gene regulation by phorbol 12myristate 13-acetate in MCF-7 and MDA-MB-231, two breast cancer cell lines exhibiting highly different phenotypes. Oncol Rep 2004 12:701-707.

17. Fogh J, Wright WC, Loveless JD: Absence of HeLa cell contamination in 169 cell lines derived from human tumors. J Natl Cancer Inst 1977, 58:209-214

18. Fukuyama N, Jujo S, Ito I, Shizuma T, Myojin K, Ishiwata K, Nagano M Nakazawa H, Mori H: Kurozu moromimatsu inhibits tumor growth of Lovo cells in a mouse model in vivo. Nutrition 2007, 23:81-86.

19. Langmuir VK, McGann JK, Buchegger F, Sutherland RM: 131Ianticarcinoembryonic antigen therapy of LS174T human colon adenocarcinoma spheroids. Cancer Res 1989, 49:3401-3406.

20. Semple TU, Quinn LA, Woods LK, Moore GE: Tumor and lymphoid cell lines from a patient with carcinoma of the colon for a cytotoxicity model. Cancer Res 1978, 38:1345-1355.

21. Weber TK, Steele G, Summerhayes IC: Differential pp60c-src activity in well and poorly differentiated human colon carcinomas and cell lines. J Clin Invest 1992, 90:815-821.

22. Lee S, Lee DK, Dou Y, Lee J, Lee B, Kwak E, Kong YY, Lee SK, Roeder RG, Lee JW: Coactivator as a target gene specificity determinant for histone $\mathrm{H} 3$ lysine 4 methyltransferases. Proc Natl Acad Sci USA 2006, 103:15392-15397.

23. Lee S, Lee J, Lee SK, Lee JW: Activating signal cointegrator-2 is an essential adaptor to recruit histone $\mathrm{H} 3$ lysine 4 methyltransferases MLL3 and MLL4 to the liver X receptors. Mol Endocrino/ 2008, 22:1312-1319.

24. Draffin JE, McFarlane S, Hill A, Johnston PG, Waugh DJ: CD44 potentiates the adherence of metastatic prostate and breast cancer cells to bone marrow endothelial cells. Cancer Res 2004, 64:5702-5711.

25. Burdall SE, Hanby AM, Lansdown MR, Speirs V: Breast cancer cell lines: friend or foe? Breast Cancer Res 2003, 5:89-95.

26. Song J, Kingston RE: WDR5 interacts with mixed lineage leukemia (MLL) protein via the histone H3-binding pocket. J Biol Chem 2008, 283:35258-35264

27. Hughes CM, Rozenblatt-Rosen O, Milne TA, Copeland TD, Levine SS, Lee JC, Hayes DN, Shanmugam KS, Bhattacharjee A, Biondi CA, Kay GF, Hayward NK, Hess JL, Meyerson M: Menin associates with a trithorax family histone methyltransferase complex and with the hoxc8 locus. Mol Cell 2004, 13:587-597.
28. Li M, Brooks CL, Wu-Baer F, Chen D, Baer R, Gu W: Mono- versus polyubiquitination: differential control of p53 fate by Mdm2. Science 2003, 302:1972-1975.

29. Elston CW, Ellis IO: Pathological prognostic factors in breast cancer. I. The value of histological grade in breast cancer: experience from a large study with long-term follow-up. Histopathology 1991, 19:403-410.

30. American Joint Committee: Manual for staging of cancer Philadelphia: J.B. Lippincott; 1998.

31. Dukes CE: Histological grading of rectal cancer. Proceedings of the royal society of medicine 1937, 30:371-376.

doi: $10.1186 / 1475-2867-10-13$

Cite this article as: Natarajan et al., Epigenetic regulator MLL2 shows altered expression in cancer cell lines and tumors from human breast and colon Cancer Cell International 2010, 10:13

\section{Submit your next manuscript to BioMed Central and take full advantage of:}

- Convenient online submission

- Thorough peer review

- No space constraints or color figure charges

- Immediate publication on acceptance

- Inclusion in PubMed, CAS, Scopus and Google Scholar

- Research which is freely available for redistribution

Submit your manuscript at www.biomedcentral.com/submit
C Biomed Central 